\title{
La reforma migratoria en Estados Unidos. Algunos efectos sobre la sociedad mexicana
}

Immigration Reform in The United States.

Some Effects Mexican Society

\author{
Federico Novelo U.*
}

Solicitamos trabajadores pero vinieron seres humanos

Max Frisch $^{* *}$

\section{Resumen}

En este artículo se hace una descripción de los antecedentes de la cuestión migratoria de Estados Unidos, así como los efectos de tal reforma para México. Asimismo se analizan las percepciones oficiales de ambos países y se muestran algunas características de la propuesta de reforma. También se evalúa el papel de las remesas de aquel país hacia el nuestro y se describe el nuevo desacoplamiento entre la oferta de la fuerza de trabajo migrante mexicana y la demanda que opera en Estados Unidos y se ofrecen algunas conclusiones.

Palabras clave:

- Migraciones internacionales

- Actividad económica internacional

- Migraciones regionales

\section{Abstract}

This article provides a description of the background of the migration issue in the United States, and the effects of such reform is to Mexico. Likewise there are analyzed the official perceptions of both countries and there appear some characteristics of the offer of reform. Also there is evaluated the paper of the remittances of that country towards ours and the new desacoplamiento is described between the offer of the workforce migrante Mexican and the demand that operates in The United States and some conclusions offer.

\section{Keywords:}

- International Migration

- International Business

- Regional Migration

JEL: F22, F23, R23

\section{Introducción}

En una suerte de tradición establecida desde 1924, la política migratoria de Estados Unidos (EU) experimentaba reformas normativas de diverso calibre, cada diez o doce años (salvo, paradójicamente, la que hubiera correspondido a los mandatos de George Bush hijo) que, al paso del tiempo, encontraron en los migrantes mexicanos indocumentados a sus más obvios destinatarios; aunque la Constitución de aquel país establece que las normas y las políticas sobre migración son competencia exclusiva del gobierno y el Congreso federales, en

$$
\begin{aligned}
& \text { * Profesor de la Universidad Autónoma Metropolitana (UAM, México), } \\
& \text { actualmente, Jefe del Departamento de Producción Económica de la UAM-Xochimilco. }
\end{aligned}
$$

\footnotetext{
** Citado en Paul R. Krugman y Maurice Obstfeld, Economía internacional. Teoría y política, Mc Graw Hill, Barcelona, 1999, p. 134. La traducción literal a Man rief Arbeitskrüfte, und es kamen Menschen, es "Importamos trabajadores, pero recibimos hombres”, frase que para Jagdish Bhagwati “... captó con belleza el hecho de que la economía y la ética son tan inseparables que debemos considerar los flujos internacionales de personas y aspirar a idear políticas para gestionarlos", J. Bhagwati, En defensa de la globalización. El rostro humano de un mundo global, Debate, Barcelona, 2005, . - . p. 310 .
} 
algunos estados de esa unión se han propuesto, y aprobado, normas -especialmente restrictivas- para enfrentar a una migración no deseada. Fue el caso de las primeras normatividades en contra de la inmigración china en California, durante 1919, y es el de las normas recientes, que arrancan en los años noventa, establecidas desde California hasta Florida, con el mismo propósito, ahora más radical, para criminalizar a los inmigrantes, a sus empleadores y a quienes les proporcionen protección humanitaria.

La xenofobia militante del nativismo blanco, visible desde la mitad del siglo XIX y ahora encarnada en el Tea Party, históricamente ha operado como una forma de presión política que por un largo período convirtió a las campanas electorales en una suerte de concurso de mala retórica anti inmigrante; hasta el último proceso electoral (noviembre de 2012), en el que el llamado voto latino mostró una musculatura muy superior a la del nativismo blanco y permitió el triunfo del Partido Demócrata en estados tan recalcitrantemente conservadores, como Texas.

La fragilidad de supuestos principios "científicos", como la Curva de Campana que coloca al coeficiente intelectual de los latinos por debajo del correspondiente a asiáticos y blancos y sólo por encima del que corresponde a la población de origen africano, o como la apología WASP (blanco, anglo sajón y protestante) que entonó, con fuertes matices racistas, el ido Samuel Huntington en su libro postrero (¿Quiénes somos?), se ilustra con la debilidad política del Tea Party y de la nutrida ala hiper conservadora del Partido Republicano.

Los resultados electorales de 2012 y, muy especialmente, las tendencias de la demografía estadounidense, han convertido en un asunto ineludible la incorporación de los habitantes de origen latinoamericano en el cálculo político electoral de todos (dos) los partidos interesados en alcanzar el poder. El cada vez más polémico presidente Barack Obama ya había ofrecido, desde la campaña de 2008, gestionar una reforma migratoria que regularizara a un número significativo de inmigrantes indocumentados. Su debilidad alterna en las Cámaras, primero de Senadores y, desde 2010, en la de Diputados, hacía poco esperanzada la posibilidad de cumplimiento; sólo el reconocimiento conservador de la fuerza del voto de inmigrantes y descendientes abrió la puerta de una negociación que ha originado la aparición de la reforma migratoria ya aprobada por el Senado y que, no sin ciertas dificultades, aprobarán los diputados. Vale la pena enfatizar que ese voto latino ha vencido, también, los lamentables efectos de la Gran Recesión, aún en curso, sobre el empleo en aquel país. 
En la tradicional provocación disfrazada de ejemplo, los integrantes del Comité Editorial de la revista Economía Informa acordamos integrar un número con nuestras propias aportaciones, en calidad de invitación para nuevos articulistas. La heterodoxia del acuerdo, en mi caso, resulta razón suficiente para participar con entusiasmo en su cumplimiento; pero hay más razones que guardan relación con el esfuerzo acumulado en el desarrollo de la revista, en el número creciente de sus lectores, en la diversificación de su Comité Editorial, en la suma de nuevos y muy calificados dictaminadores y en el marco de acción y logros de la actual administración de la Facultad de Economía de la UNAM y de sus académicos, que operan en un ambiente de tolerancia, diálogo y cooperación que, siendo prendas indispensables de la vida universitaria, no solían adornar a la de esta Facultad.

En el presente trabajo, se hace una descripción de los antecedentes de la cuestión migratoria y las percepciones oficiales dominantes en Estados Unidos y en México; se muestran las características de la reforma en curso, se evalúa el papel, menguado y menguante, de las remesas de aquel país al nuestro, se describe el nuevo desacoplamiento entre la oferta de la fuerza de trabajo migrante mexicana y la demanda que opera en Estados Unidos y se arriba a un cuerpo, breve, de conclusiones.

El retorno, por mi parte, a la cuestión migratoria, se ha incentivado con la reforma precitada y con las contradictorias perspectivas que ofrece a nuestros migrantes, más allá del marco del Tratado de Libre Comercio de América del Norte (TLCAN), en el que no tuvo cabida la propuesta foxista del entonces convertible en NAFTAPLUS: comenzamos.

\section{Antecedentes}

Tanto a la luz de los incentivos, los espacios de origen y destino, y las magnitudes, los flujos migratorios internacionales, entre la etapa de mayor intensidad -durante el último tercio del siglo XIX- y la actual -caracterizada por un nuevo momento de la globalización-, a partir de 1989 (año del derrumbe del Muro de Berlín y, sobre todo, de la formalización del llamado Consenso de Washington), muestran muy pocas similitudes y notables diferencias.

La vieja migración fluyó principalmente de los países antiguos a los nuevos, fue impulsada por factores de expulsión (como las tecnologías ahorradoras de fuerza de trabajo, y las consecuentes reducciones salariales) y de atracción (como los requerimientos de mano de obra calificada en incipientes procesos 
de industrialización) y significó alrededor de 10\% de la población mundial de la época. Según Martin Wolf:

En los cuarenta años previos a la Primera Guerra Mundial, la migración aumentó la fuerza de trabajo en el Nuevo Mundo en un tercio y redujo la fuerza de trabajo europea en un octavo. Estas cifras no han sido superadas ni siquiera por California y México durante los últimos cuarenta años ${ }^{1}$

La vieja migración contó, también, con el beneplácito de las sociedades anfitrionas que, en muchos casos, hospedaron nuevas zonas de asentamientos recientes.

La nueva migración fluye principalmente de los países pobres a los países ricos; es impulsada, en lo fundamental por los notables diferenciales en salario y comporta la movilización de alrededor de 3\% de la actual población mundial (191 millones de personas). ${ }^{2}$ Como factor de expulsión opera una deliberada política, establecida por los gobiernos de los países de origen, que promueve el desarrollo preferente del mercado externo, castigando al interno, mismo que en las sociedades plurales y heterogéneas (¿cuál no lo es actualmente?), representa el más significativo elemento de cohesión social. Cuando el mercado interno es estratégico, tal relevancia se hace visible por medio de los aumentos recurrentes del salario real; cuando no es así, acontece lo inverso. ${ }^{3}$ Esta nueva migración produce, en las sociedades de destino, sentimientos encontrados: Se juzga necesaria en lo económico e inconveniente en lo social; los inmigrantes son necesarios, pero no son bienvenidos. ${ }^{4}$

Un especialista en el tema migratorio propone tres factores de transformación que, verificados al calor de la globalización, explican el hecho notable por el que el número de personas que residen por más de un año en un país distinto al que nacieron, pasó de 150 millones en el año 2000 a 191 millones en la actualidad; los factores propuestos son:

a) "El crecimiento de las desigualdades internacionales e internas en los países;

b) La percepción de esas desigualdades $-\mathrm{y}$ de las oportunidades de reducirlas a

1 Martin Wolf, "Humanity on the Move:The Myths and Realities of International Migration”, The Financial Times, 30 de julio de 2003, p. 11, citado en Bhagwati Jagdish, En defensa de la globalización, Debate, Barcelona, 2005, p. 312.

2 Joaquín Arango, "Las migraciones internacionales en un mundo globalizado", Vanguardia (Dossier) Inmigrantes. El continente móvil, número 22, enero-marzo 2007, p. 9.

3 Consultar: Celso Furtado, El capitalismo global, FCE, México, 1998, pp. 42-56.

4 Joaquín Arango, "Las migraciones...", loc. cit. 
través de la movilidad- se vuelve más aguda e inmediata por la penetración de los medios de comunicación globales, y

c) El desplazamiento físico se ha visto facilitado por el progreso en los transportes internacionales". 5

Para el mundo contemporáneo, la relevancia de los migrantes resulta de muy difícil exageración:

En positivo y en negativo representan hoy el principal factor de transformación social, cultural y demográfica en muchos países avanzados. Si desaparecieran o fueran a la huelga todos juntos, en todo el mundo, el mismo día, las sociedades y las economías de los países ricos se verían descalabradas: cultivos que se pudrirían en los campos, ciudades congestionadas por las basuras, talleres cerrados, ancianos no autosuficientes abandonados solos, oleadas enteras de padres obligados a ausentarse del trabajo para atender a sus hijos, y descensos de la productividad en todos los sectores. En el lado opuesto, los países y las regiones con mayores tasas de emigración, privados de la crucial amortización social que suponen los envíos de dinero, se arriesgarían al colapso. ${ }^{6}$

El fenómeno produce ambivalencias, tanto en las sociedades de destino como en las de origen: Para las primeras, la inmigración resulta, simultáneamente, necesaria e indeseable; para las segundas, se tiene una fe profunda en el supuesto carácter salvador de las remesas, combinada con un gran temor a la fuga de cerebros. Este panorama, entre otros efectos, propicia una notable opacidad a la hora de definir el interés nacional, en el diseño de las políticas migratorias.

Los agentes económicos, en el ambiente dominado por el mercado y sus notables fallas, responden a incentivos, positivos o adversos, para definir sus decisiones fundamentales. ¿Por qué emigra una proporción tan significativa de la población mexicana en edad de trabajar hacia los Estados Unidos? La reflexión relativa a la importancia de los incentivos materiales y la comparación de los indicadores básicos, arroja la respuesta:

... las leyes malas u opresivas, los impuestos elevados, un clima poco atractivo, un entorno social desagradable e incluso la coacción (comercio de esclavos, deportación) han producido y siguen produciendo corrientes migratorias, pero ninguna

5 Ferruccio Pastore, "El continente móvil. Migraciones y relaciones internacionales", Vanguardia (Dossier) Inmigrantes. El continente móvil, número 22, enero-marzo 2007, p. 110.

6 Ídem., loc. cit. 
de estas corrientes se puede comparar en volumen con las que surgen del deseo inherente de la mayoría de los hombres a prosperar en el aspecto material. ${ }^{7}$

Las grandes diferencias, económicas y sociales, que existen entre los Estados Unidos y México, conforman un caso único en todo el planeta: "La distancia de renta entre Estados Unidos y México es la mayor del mundo entre dos países contiguos". "Las asimetrías no se agotan en los diferenciales de ingreso y guardan relación con un amplio espectro de indicadores; quizá el mayor problema corresponde al alejamiento de las posibilidades de convergencia.

La profundización en la disparidad de ingresos entre países ricos y pobres constituye un fuerte incentivo para aumentar la presión para emigrar a los primeros, que responden erigiendo barreras más altas a la inmigración y a las importaciones primarias. En este sentido, el gran supuesto del consenso de Washington, en el que los mercados libres acarrearían la convergencia económica, es erróneo; de la misma forma que es equivocado el mito liberal, mediante el que las sociedades que se modernizan, se asemeja. ${ }^{9}$ El uniformismo que deriva de imaginar que hay un sólo sistema económico compatible con las exigencias de la modernidad favorece la negación de oportunidades, especialmente a los países pobres, para buscar los mecanismos de su propio desarrollo, sin subordinación a los planteamientos económicos impuestos desde los organismos multilaterales, en los que la sobre representación de los países ricos es totalmente visible. Más de una evidencia mueve a afirmar que, hasta ahora, la globalización no arroja resultados plausibles, según nos muestran: la extensión y profundización de la pobreza, la desigualdad entre las naciones y a su interior, el magro listado de ganadores y la interminable lista de perdedores, las soberanías nacionales aplastadas, el páramo ambiental, la devastadora actividad del dinero caliente y, especialmente, la rigidez de los organismos responsables de promover la estabilidad y el crecimiento de las naciones, visiblemente lejana de lo acordado en Bretton Woods. La llamada hipótesis de convergencia, que sugiere un crecimiento más acelerado en las economías de los países pobres que se vinculan a los países ricos, en un ambiente de libre comercio y libertad para

7 E. G. Ravenstein, "The Laws of Migration”, en Journal of the Royal Statistical Society, Londres, 1885-1889, p. 286, citado en Joaquín Arango, La explicación teórica de las migraciones: Luz y sombra, en la revista Migración y Desarrollo, número 1, Red Internacional Migración y Desarrollo, Universidad Autónoma de Zacatecas, México, octubre de 2003, p. 6.

8 David M. Kennedy, “Can We Still Afford to Be a Nation of Immigrants?”, Atlantic Monthly, núm. 278, noviembre de 1996, p. 67, citado en Samuel Huntington, ¿Quiénes somos? Los desafíos a la identidad nacional estadounidense, Paidós, Estado y sociedad, México, 2004, pp. 260-261.

9 John Gray, Las dos caras del liberalismo, Paidós, España, 2001, p. 34, México. 
el tránsito de las inversiones -a escala global-, se ve más que desmentida por las evidencias disponibles.

Estas disparidades operan como un poderoso incentivo para la migración de los países pobres a los ricos y, en tal tendencia, el caso de la migración mexicana hacia Estados Unidos no puede representar ninguna excepción. La singularidad de estos flujos en particular descansa en su prolongada duración, en su carácter masivo, en la vecindad entre México y los Estados Unidos, en la creciente diversificación de los lugares de origen y destino, en la que corresponde a las actividades productivas donde habrá de emplearse y, en general, en la que es relativa a la evolución del perfil del migrante.

Existe un duradero proceso de búsqueda de oportunidades de ocupación en Estados Unidos, por parte de la mano de obra mexicana, que se originó en la porción de la población de México que se mantuvo en los territorios que, tras la invasión estadounidense al país y la firma de los Tratados GuadalupeHidalgo en 1848, le fueron arrebatados por Estados Unidos; continuó en la construcción del ferrocarril en este país, y en la cosecha de los cultivos diversos del Sur estadounidense. En opinión de dos reconocidos expertos en el tema migratorio: "La migración entre México y los Estados Unidos es un fenómeno centenario y muy probablemente es el flujo migratorio contemporáneo con mayor antigüedad en el ámbito mundial". ${ }^{10}$ La referencia a un efecto peculiar, de separación de espacios que, antes de la pérdida de parte significativa del territorio mexicano, conformaban unidades, ${ }^{11}$ tiende a favorecer el examen de la migración, no en la opción de aquella población fronteriza por pertenecer a uno u otro lado de la nueva frontera, sino a partir de los flujos provenientes del interior de México. Así, durante la segunda mitad del siglo XIX, el flujo migratorio encuentra un incentivo fundamental en la conexión ferrocarrilera de la estación Paso del Norte, Chihuahua, que -al tiempo que recibía al Ferrocarril Central Mexicano, desde la Ciudad de México- facilitaba que los mismos vagones se engancharan a los ferrocarriles de

10 Jorge Durand y Douglas S. Massey, Clandestinos. Migración México- Estados Unidos en los albores del siglo XXI, Miguel Ángel Porrúa, México, 2003, p. 45.

11

\begin{tabular}{|l|l|l|}
\hline Nombre Original & Lado Mexicano & Lado Estadounidense \\
\hline Paso del Norte & Ciudad Juárez & El Paso \\
\hline Laredo & Nuevo Laredo & Laredo \\
\hline Nogales & Nogales & Nogales \\
\hline
\end{tabular}

Fuente: J.Durand y D. S. Massey, Clandestinos..., op. cit., p. 46. 
Economía Informa núm. 386 mayo - junio • 2014

la Atchinson-Topeka-Santa Fe, Southern Pacific, Texas-Pacific y GalvestonHarrisburg-San Antonio.

Durante el siglo xx, algunos especialistas proponen una periodización, en cinco etapas, que arrancan en 1900 y, en cada caso, muestran una duración de entre 20 y 22 años. La primera, denominada también fase del enganche, llega hasta y 1920 y es el resultado de tres factores diferenciados:

a) El sistema de contratación de mano de obra privado y semiforzado, conocido como el enganche;

b) La Revolución mexicana y su secuela de decenas de miles de refugiados, y

c) El ingreso de Estados Unidos a la Primera Guerra Mundial, que limitó la llegada de nuevos inmigrantes europeos y demandó, de manera temporal, mano de obra barata, joven y trabajadora, proveniente de México.

La segunda fase, conocida también como la de las deportaciones, se sintoniza con los antecedentes, el estallido y las consecuencias de la Gran Depresión y se combina con el surgimiento y primeras operaciones de la Patrulla Fronteriza (1924). Se verifican en esta fase tres momentos de deportación masiva y uno de deportaciones cotidianas. De las primeras, se parte de la realizada en 1921, por razones coyunturales y con una rápida recuperación del flujo inmigrante; la segunda - de mucho más severos efectos sobre las redes y circuitos migratorios- se verifica entre 1929 y 1932, y la última, en 1939, se amortiguó por los programas de colonización agraria y de promoción agropecuaria del cardenismo.

La tercera fase corresponde totalmente al período que abarcaron las diversas ediciones de los programas bracero, que respondían a los requerimientos estadounidenses de trabajadores, especialmente agrícolas, que derivaron de la participación en la Segunda Guerra Mundial. El auge postbélico amplió el programa por otras dos décadas y, tras su conclusión formal, aun alcanzó una débil prolongación, de hecho, hasta 1967.

A partir de 1965, inicia la cuarta fase que también se conoce como la era de los indocumentados (1965-1986). Tras decidir unilateralmente la conclusión de los convenios braceros, el gobierno de Estados Unidos también decidió dar un trato unilateral a la inmigración de trabajadores mexicanos, con apoyo en tres instrumentos: La legalización de una parte de ellos, bajo el sistema de cuotas por país; la llamada institucionalización de la frontera para dificultar el paso y limitar el libre tránsito y la deportación sistemática de los indocumentados. 
La última fase del siglo xx se inicia en 1987 con la puesta en marcha de la Immigration Reform and Control Act (IRCA), y conforma una etapa de legalización combinada con migración clandestina. Es una reforma legal, también conocida como Simpson-Rodino, que modifica radicalmente el modelo migratorio de ida y vuelta que caracterizó a los programas bracero, tanto a la luz de una amplia amnistía (LAw) y del programa de trabajadores agrícolas especiales (SAW), que permitieron la legalización de más de 2.3 millones de mexicanos indocumentados. Con todo, la cobertura de la amnistía es mucho menos que incompleta y, de otro lado, la reforma legal introduce la aplicación de sanciones para empleadores de indocumentados; de ahí la emergencia de la clandestinidad, ${ }^{12}$ con la falsificación o la simulación de documentos.

Al menos por tres poderosas razones, la antigua, numerosa y cercana migración México-Estados Unidos encierra una relevante singularidad; es la más prolongada de las migraciones hoy relevantes, significa una movilización creciente de mexicanos y se sirve de la ancha frontera compartida por ambas naciones. La historicidad, la masividad y la vecindad otorgan sentido a la afirmación relativa al carácter singular de estos flujos migratorios. ${ }^{13}$

\section{Cuadro 1}

Población mexicana neta anual perdida por la migración a Estados Unidos

por periodo, 1961/2005(miles)

\begin{tabular}{|c|c|}
\hline Periodo & Miles de personas \\
\hline $1961 / 1970$ & 27.5 \\
\hline $1971 / 1980$ & 137.5 \\
\hline $1981 / 1990$ & 235.0 \\
\hline $1991 / 1995$ & 296.0 \\
\hline $1996 / 2000$ & 360.0 \\
\hline $2001 / 2005$ & 396.0 \\
\hline
\end{tabular}

Fuente: Elena Zúñiga Herrera y Paula Leite, Los procesos contemporáneos de la migración México-Estados Unidos: Una perspectiva regional, en el libro: Elena Zúñiga H., Jesús Arroyo A., Agustín Escobar L. y Gustavo Verduzco I, Migración México-Estados Unidos. Implicaciones y retos para ambos países, México, 2006, p. 54.

12 Este fenómeno, sin duda, tenderá a profundizarse con la muy reciente aprobación, por parte de la Cámara de Representantes (y seguramente, en su momento, del Senado) de Estados Unidos del proyecto de ley antiinmigratorio Real ID (Identificación Auténtica), también conocido por las siglas HR 418, iniciativa del congresista James Sensenbrenner, republicano por supuesto, que cuenta con el apoyo de G. W. Bush. Cfr. Diario El País, martes 15 de febrero de 2005, p. 9.

13 Durand, Jorge y Massey, Douglas, Clandestinos..., op. cit., pp. 45-61. 


\section{La reforma migratoria actual}

\begin{tabular}{|c|c|c|c|}
\hline \multicolumn{4}{|c|}{$\begin{array}{l}\text { Cuadro } 2 \\
\text { La reforma migratoria en Estados Unidos, ¿cuántos y quiénes se beneficiarían por } \\
\text { región de origen? }\end{array}$} \\
\hline \multirow{2}{*}{ País/región de origen } & \multicolumn{3}{|c|}{$\begin{array}{c}\text { Migrantes no documentados que podrían obtener el estatus de } \\
\text { Inmigrante Provisional Registrado (RPI) }\end{array}$} \\
\hline & Total & Dreamers* & $\begin{array}{l}\text { Trabajadores } \\
\text { agrícolas* (Blue Card) }\end{array}$ \\
\hline México & $\begin{array}{l}5400000 \\
\text { a } 680000\end{array}$ & $\begin{array}{l}760000 \\
\text { a } 825000\end{array}$ & 150000 \\
\hline Asia & 2255000 & 245000 & $<5000$ \\
\hline Centroamérica & 955000 & 105000 & $<10000$ \\
\hline Europa & 655000 & 90000 & n.d. \\
\hline Sudamérica & 695000 & 90000 & n.d. \\
\hline El Caribe & 525000 & 90000 & $<10000$ \\
\hline África & 410000 & 35000 & n.d. \\
\hline Oceanía & 50000 & 10000 & n.d. \\
\hline Canadá & 140000 & 30000 & n.d. \\
\hline Total & 11.1 a11.5 millones & 1.43 a 1.58 millones & 180000 \\
\hline
\end{tabular}

Fuente: BBva Research.

\section{Gráfica |}

\section{Proporción de migrantes mexicanos y centroamericanos} en Estados Unidos, según nivel educativo, 2012

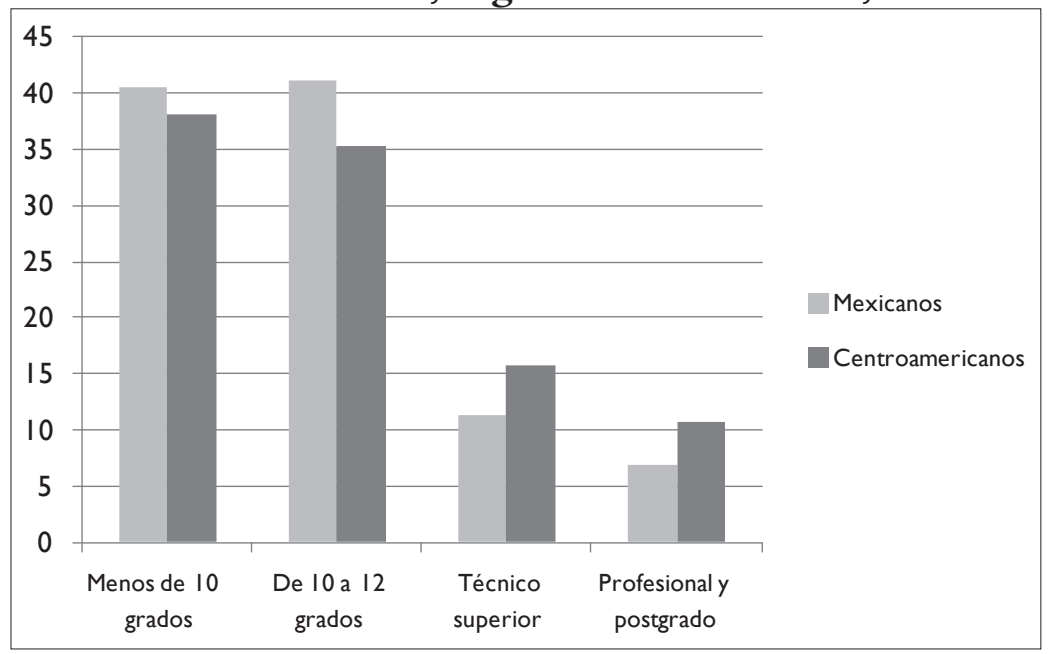

Fuente: BBVA Research con cifras de la Current Population Survey. 


\section{Gráfica 2}

Recepción de remesas privadas en 2012, estimaciones del Banco

\section{Mundial}

(miles de millones de dólares)

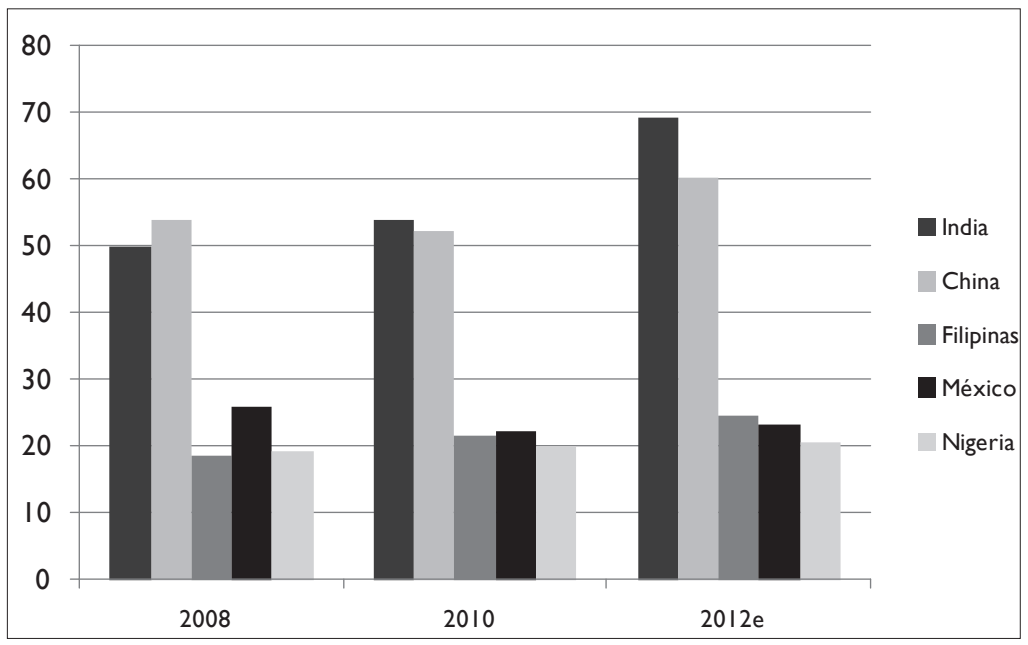

\section{Gráfica 3}

Compensaciones laborales por empleado entre

Estados Unidos y México

(dólares ajustados por paridad del poder adquisitivo)

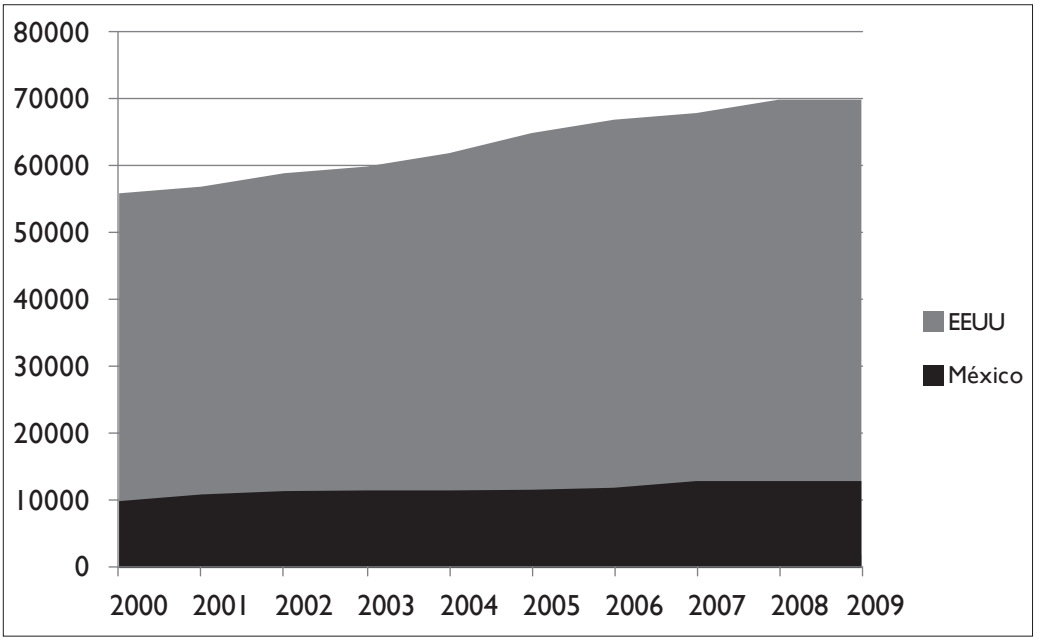

Fuente: BBVA Research con cifras de la OCDE. 


\section{Gráfica 4}

Flujo anual de inmigrantes mexicanos a Estados Unidos y tasa crecimiento del PIB, 1991-2012

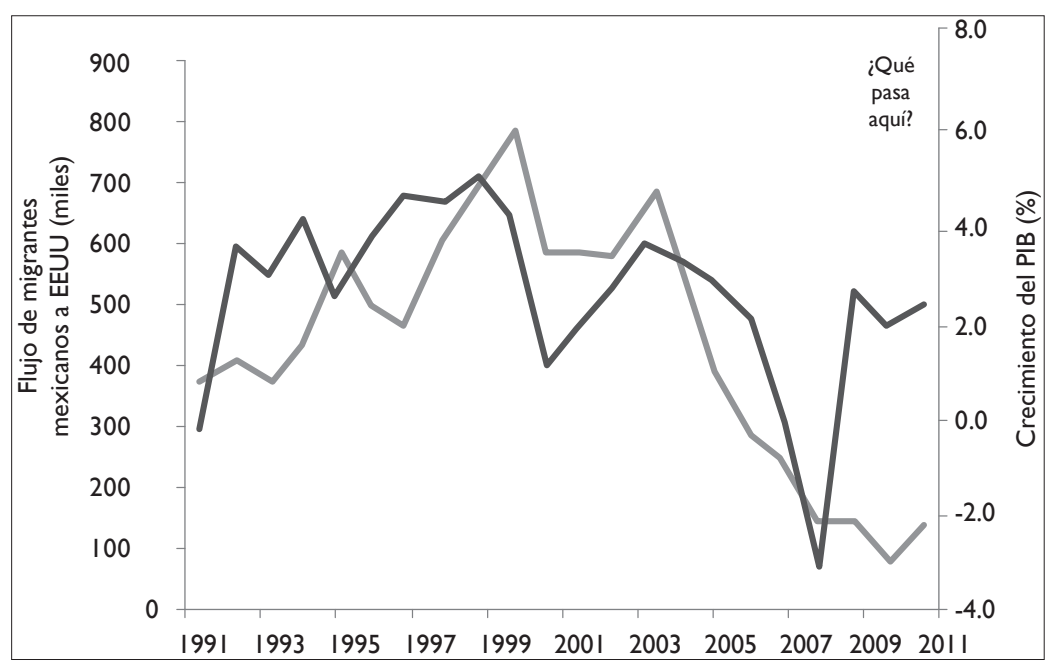

Fuente: BBVA Research con cifras de Passel, et. al (2012) y u.s. Bureau of Economic Analysis (BEA).

Nota: las cifras del flujo migratorio son estimaciones del BBVA Research a partir de 2011.

\section{Gráfica 5}

Estados Unidos: mexicanos aprehendidos por la patrulla fronteriza y crecimiento de PIB

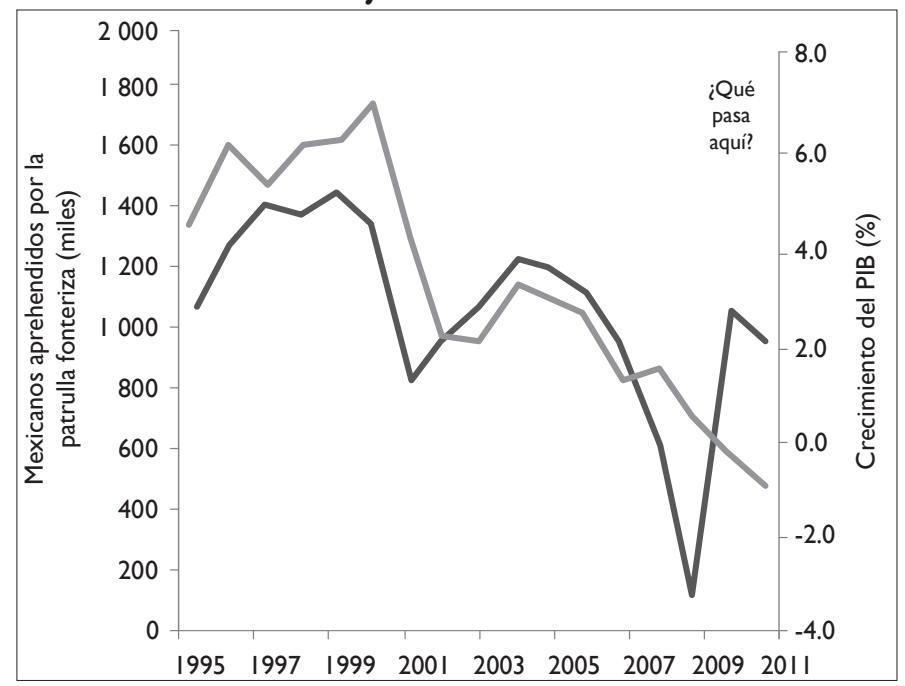

Fuente: bbva Research con cifras de Departament of Homeland Security y u.s. Bureau of 


\section{Gráfica 6}

Estados Unidos: Porcentaje de empleados por nivel educativo (promedio de 2009 a 2012)

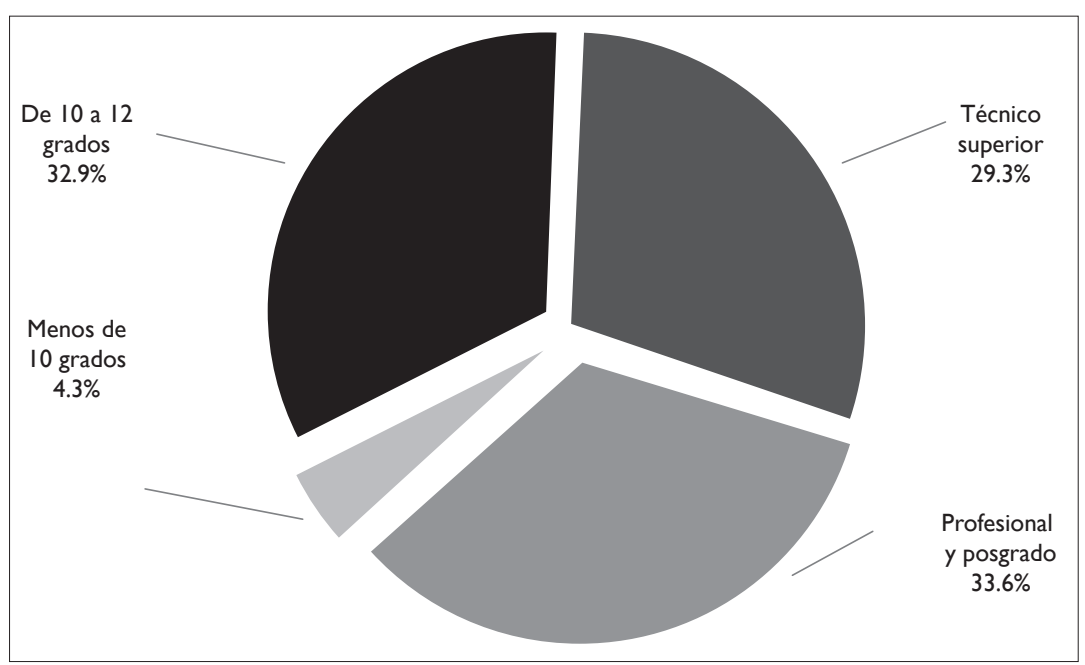

Fuente: BBVA Research con cifras de la Current Population Survey.

\section{Gráfica 7}

Estados Unidos: porcentaje de migrantes mexicanos empleados por nivel educativo

(promedio de 2009 a 2012)

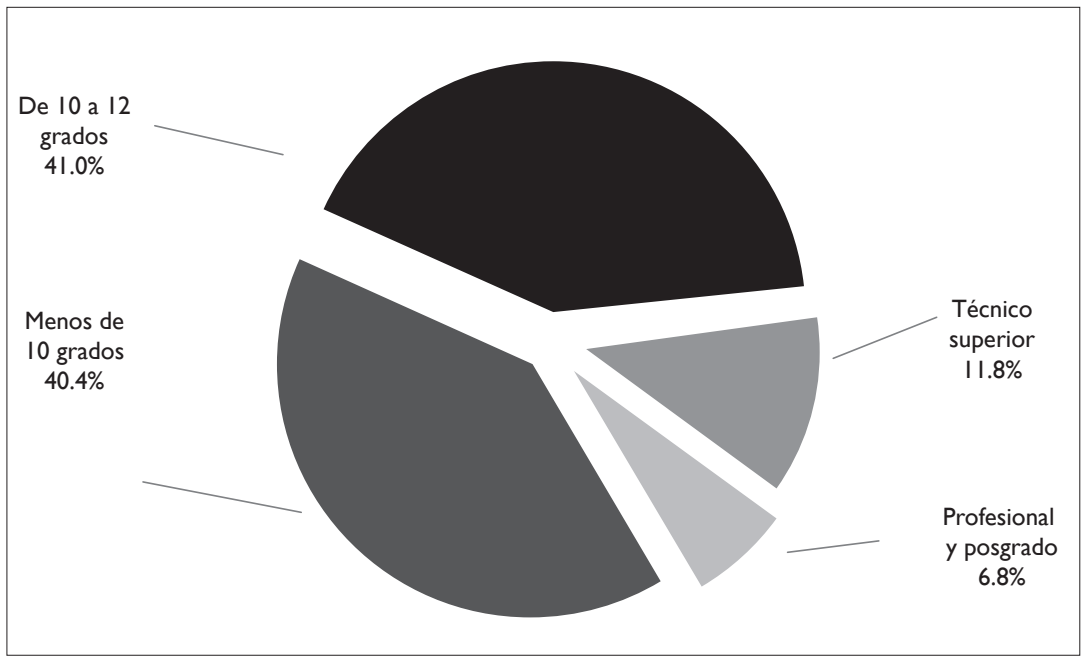

Fuente: BBva Research con cifras de la Current Population Survey. 